\title{
Effect of Nano Silicon Dioxide Addition on Some Properties of Heat Vulcanized Maxillofacial Silicone Elastomer
}

\author{
Mustafa S. Tukmachi ${ }^{1}$, Mohammed Moudhaffer M. Ali ${ }^{2}$ \\ ${ }^{1}$ M.Sc. Student (Department of Prosthodontics, College of Dentistry/ University of Baghdad, Iraq) \\ ${ }^{2}$ Assist. Prof. (Department of Prosthodontics, College of Dentistry/ University of Baghdad, Iraq)
}

\begin{abstract}
Silicone elastomer is widely used as the material of choice for fabricating maxillofacial prosthesis. However, silicone properties are far from ideal; low tear strength, low tensile strength and insufficient elasticity are the most undesirable properties. The purpose of this study was to evaluate the effect of addition of nano $\mathrm{SiO}_{2}$ filler on tear strength, tensile strength, elongation at break, hardness and color of Cosmesil M-511 HTV maxillofacial silicone elastomer. Nano $\mathrm{SiO}_{2}$ was added to the silicone base in concentrations of 4\%, 5\% and 6\% by weight. Silicone with $0 \%$ nano filler served as a control. Tear test was done according to ISO 34-1. Tensile and elongation test was done according to ISO 37. Shore A hardness test was done according to ISO 7619. Visual color measurement test was done according to ASTM D1535. Scanning electron microscope was used to assess the efficiency of dispersing method. FTIR test was conducted to evaluate the interaction of nano $\mathrm{SiO}_{2}$ with the silicone. Statistical analysis was done using one-way ANOVA and Fisher's LSD test. SEM showed well dispersion of nano filler within the silicone matrix. FTIR indicated that nano $\mathrm{SiO}_{2}$ interacted with the PDMS through its surface hydroxyl group. All nano $\mathrm{SiO}_{2}$ concentration groups showed a highly significant increase in tear strength, tensile strength and elongation at break compared to the control group. The 5\% group showed the highest mean values among other groups. Shore A hardness showed a highly significant increase with all nano $\mathrm{SiO}_{2}$ concentrations with the increase being directly proportional to filler concentration increase. Spectrophotometer results showed a highly significant decrease in translucency of the material with all nano filler concentrations but this decrease in translucency was visually demonstrated as slight increase in color intensity. Reinforcement of M-511 silicone with 5\% nano $\mathrm{SiO}_{2}$ significantly improves all mechanical properties tested with a slight change of color seen visually.
\end{abstract}

Keywords: HTVmaxillofacial silicone, nano $\mathrm{SiO}_{2}$, tear strength, tensile strength, Shore A hardness.

\section{Introduction}

Body abnormalities or defects that compromise appearance, function and render an individual incapable of leading a relatively normal life have usually prompted responses that seek to bring the person to a state of being acceptable normally. In response to congenital or acquired defects, man has continually sought to cope with his debilities by using his genius and the material resources available for restoration. Facial disfigurement can be the result of a congenital anomaly, trauma or tumor surgery. Surgical reconstruction may not be possible owing to size or location of the defect. The patient's medical condition or personal desires may also preclude reconstructive surgery. In such cases, prosthetic rehabilitation is indicated [1].

Different materials have been used in the past to fabricate maxillofacial prosthesis including ivory, wax, metal, wood and recently polymers such as silicone elastomers, polyurethane elastomers and acrylic resins[2]. Since the introduction of silicone elastomer by Barnhart in 1960, it has been widely used as the material of choice for fabricating maxillofacial prosthesis because of its chemical inertness, durability, ease of manipulation and biocompatibility[3-5].

Silicone elastomeric materials, chemically known as polydimethylsiloxane (PDMS), possess some undesirable properties; most important are low tensile and tear strength, insufficient elasticity and degradation of physical and color properties[6].

The mechanical properties of a silicone elastomer are dependent on many factors including molecular weight of polymer chains, incorporation of filler and cross-link density[7]. In the chemical industry, during the past 15 years, research has been devoted to the development of a new industrial process that incorporates nanoparticles into a polymeric matrix, providing a new class of polymeric materials that offers the strength of the nano-oxides, with the flexibility of organic polymer[8,9].

Nano-sized $\mathrm{SiO}_{2}$ is characterized by its small size, large specific area, active function, and strong interfacial interaction with the organic polymer[10].

The purpose of this study was to evaluate the effect of addition of different weight concentrations (4\%, $5 \%$ and $6 \%$ ) of nano $\mathrm{SiO}_{2}$ on tear strength, tensile strength, elongation at break, hardness and color of Cosmesil M-511 HTV maxillofacial silicone elastomer. 


\section{Materials and Method}

Materials used in this study are listed in Table 1. One hundred and sixty (160) specimens were fabricated and divided into 4 groups according to the tests conducted (Tear strength, tensile strength and elongation, shore A hardness and color change tests) with 40 specimens for each test. The color change tests consisted of two tests, spectrophotometer light transmission test and Munsell visual color measurement test, with 20 specimens each. Each group was then divided into four subgroups according to weight percentage of nano filler: Group A with 0\% (control), group B with 4\%, group C with 5\% and Group D with 6\%) with 10 specimens each except for the color change tests with 5 specimens each.

Table 1: Materials used in the study

\begin{tabular}{|l|l|l|}
\hline Material & Manufacturer & Patch number \\
\hline $\begin{array}{l}\text { Cosmesil M-511 HTV Maxillofacial Silicone Elastomer (Part } \\
\text { A and B) }\end{array}$ & Factor II Inc., USA & 121112 \\
\hline $\begin{array}{l}\text { Silicon Oxide nanopowder (SiO } 2 \text { Nanoparticles 99.5+\% } \\
\text { purity, 15-20 nm, porous and amorphous) }\end{array}$ & US Research Nanomaterials, USA & 3440 \\
\hline FI-SK07 Silicone Functional Intrinsic Cream Color & Factor II Inc., USA & S 070312 \\
\hline
\end{tabular}

Four metal molds, one for each test, were prepared by cutting cast iron sheets with plasma CNC machine. Each mold contained 12 specimen holes that were cut into the specified dimension for each test. The thickness of the iron sheet used for tear, tensile and color change tests was $2 \mathrm{~mm}$ and the sheet used for hardness test was $6 \mathrm{~mm}$ (Fig. 1). For each metal mold, two glass slabs were cut with the same outer dimensions of the metal mold to sandwich the mold between them.

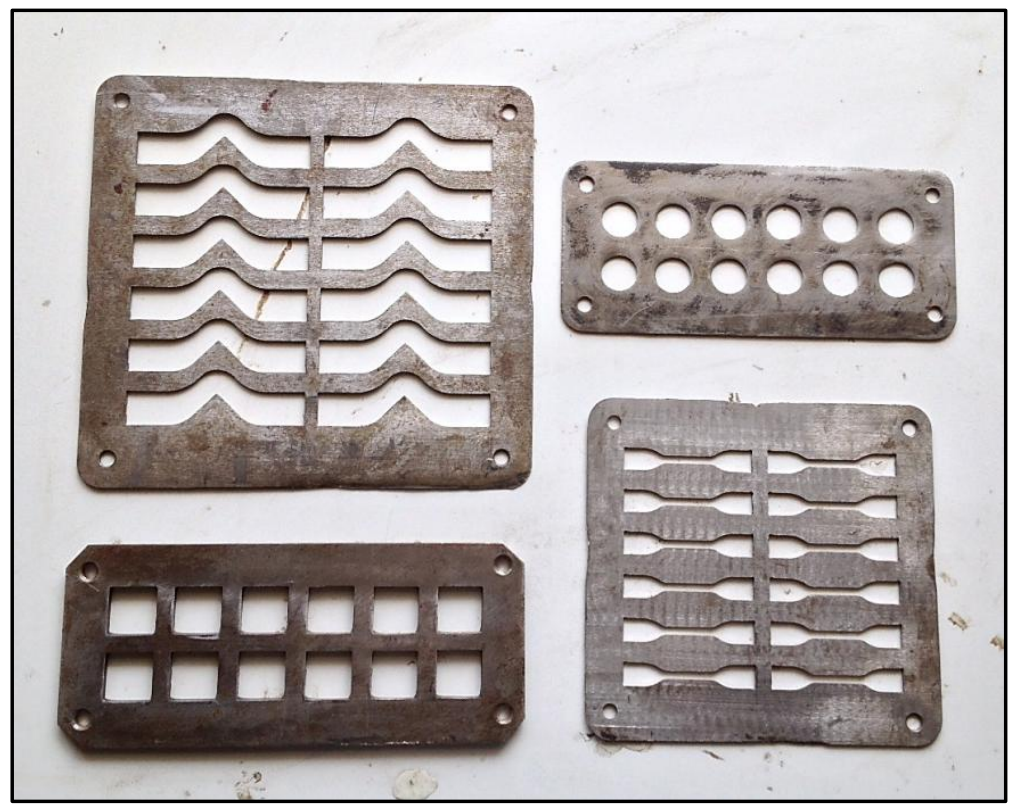

Figure 1: Metal molds

The Cosmesil M-511 maxillofacial silicone is a 2-part platinum (vinyl addition) cure system that requires curing in a hot air oven at $100^{\circ} \mathrm{C}$ for an hour. It has 1-hour working time. According to manufacturer instructions, the mixing ratio is 10:1 base (part A) to crosslinker (part B) by weight. An intrinsic cream color was added in amount of $0.5 \%$ of the total weight to all specimen groups.

For preparing specimens of group A (Control group), part A and part B of M-511 silicone and colorant were weighed using electric balance and were mixed by a vacuum mixer (Multivac 3; Degussa, Germany) [11] for 5 minutes at speed of $360 \mathrm{rpm}$ and under vacuum of -10 bar.

For specimens of group B, C and D, Part A and nano filler were weighed first then were mixed by the vacuum mixer for 10 minutes; the vacuum was turned off for the first three minutes to avoid suction of the nano filler and it was turned on for the remaining 7 minutes. The mixing bowl was set aside to cool down to room temperature as heat was generated during mixing then part B and colorant were weighed and added to the mixture and mixed in the vacuum mixer for 5 minutes (Fig. 2). 


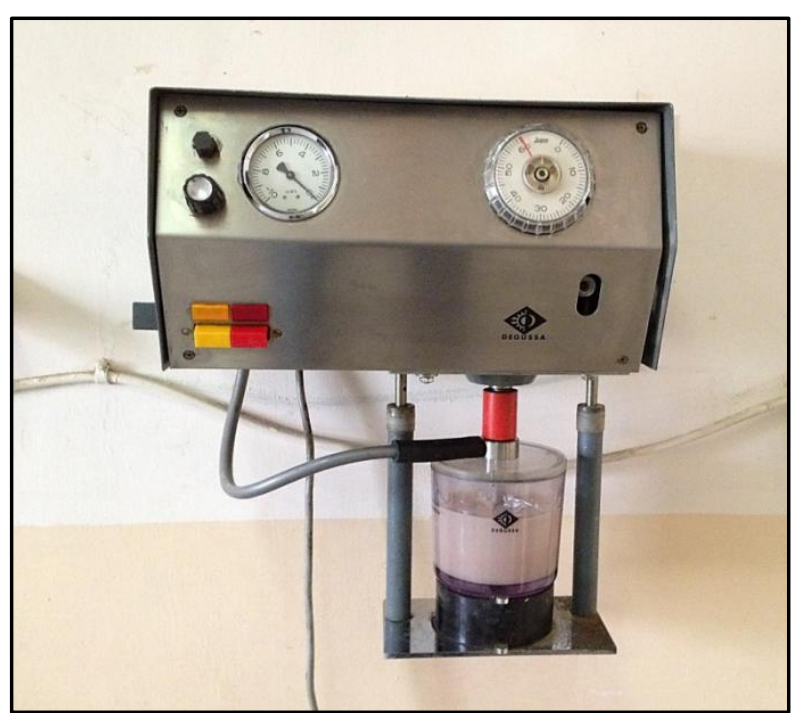

Figure 2: Vacuum mixer

The mixture was then loaded in a $50 \mathrm{ml}$ plastic syringe and injected into the metal molds and transferred to a vacuum chamber for 2 minutes to eliminate all air bubbles incorporated during molding. Afterwards, the molds were closed with the glass slab and pressed by G-clamps and curing of material was done in a hot air oven at $100^{\circ} \mathrm{C}$ for one hour. After curing, the molds were carefully separated, specimens were removed, and the flush and excess material was removed by a scalpel and blade no. 11. Samples were stored away from light and heat until tested. All tests were done under standard laboratory conditions, i.e. the temperature of $23 \pm 2{ }^{\circ} \mathrm{C}$ and relative humidity of $50 \% \pm 10 \%$, and the minimum time between vulcanization and testing was 16 hours. Tear test was done according to ISO 34-1:2010 [12]. An angle test specimen without nick was fabricated and the thinness of the specimens was measured using digital caliper at area of the right angle. The specimens were mounted on a universal testing machine (H10KT; Tinius Oslen, USA) and stretched at a rate of $500 \mathrm{~mm} / \mathrm{min}$ of grips separation until it breaks. The maximum force at break was then recorded and tear strength was calculated. Type 2 dumb-bell specimens were fabricated according to ISO 37:2011[13] to be tested for tensile strength and elongation. Thickness of the specimens was measured at the narrow portion by a digital caliper. The specimens were mounted on a universal testing machine (H10KT; Tinius Oslen, USA) and stretched at a rate of $500 \mathrm{~mm} / \mathrm{min}$ of grips separation until it breaks. The maximum force at break was then recorded and tensile strength was calculated. Elongation at break was calculated using an extensometer.

Shore A hardness test was done according to ISO 7619-1:2010 [14]. A square-shaped specimen was fabricated. Five readings were made on each specimen $(6 \mathrm{~mm}$ apart) using a digital Shore A durometer with a blunt indenter of diameter of $1.25 \mathrm{~mm}$. The average of the five readings was calculated and considered the hardness number of the specimen. Disc sample with diameter of $20 \mathrm{~mm}$ and thickness of $2 \mathrm{~mm}$ was prepared for color change tests [15]. Light transmission test was done using a spectrophotometer (UV-160A; Shimadzu, Japan). Munsell visual color test was done according to ASTM D1535-13 [16]. The sample was compared with the color tabs until a match was found then the color notation was recorded. The color difference was calculated by using the Nickerson equation [17], which is:

$I=(C / 5)(2 \Delta H)+6 \Delta V+3 \Delta C$

where $I$ is the color difference, $C$ is the average chroma and $\Delta H, \Delta V$ and $\Delta C$ are differences in hue, value and chroma of the two colors. One sample from each nano filler concentration group was examined under scanning electron microscope to evaluate the efficiency of dispersing method. FTIR test was conducted to evaluate the interaction of nano $\mathrm{SiO}_{2}$ with the silicone using FTIR spectrometer (8400S; Shimadzu, Japan). Statistical analysis was done using one-way ANOVA and Fisher's LSD test.

\section{Results}

All experimental groups (Group B, C and D) showed highly significant increase in mean values for tear strength, tensile strength, elongation at break and Shore A hardness; group $\mathrm{C}\left(5 \% \mathrm{SiO}_{2}\right)$ was the highest among other groups for tear strength, tensile strength and elongation at break while group $\mathrm{D}\left(6 \% \mathrm{SiO}_{2}\right)$ was the highest among other groups for Shore A hardness. For Light transmission test, all experimental groups showed highly significant decrease in mean values with group $\mathrm{D}\left(6 \% \mathrm{SiO}_{2}\right)$ was the lowest among other groups. Table 2 summarizes the mean values obtained from each test conducted. 
Table 2:Mean values of conducted tests

\begin{tabular}{|c|c|c|c|c|c|}
\hline & $\begin{array}{c}\text { Tear strength } \\
(\mathrm{N} / \mathrm{mm})\end{array}$ & $\begin{array}{c}\text { Tensile strength } \\
(\mathrm{MPa})\end{array}$ & $\begin{array}{c}\text { Elongation at break } \\
\text { (percentage) }\end{array}$ & $\begin{array}{c}\text { Shore A } \\
\text { hardness }\end{array}$ & $\begin{array}{c}\text { Light transmission } \\
\text { (Percentage) }\end{array}$ \\
\hline \begin{tabular}{c} 
Group A 0\% \\
\hline $\mathrm{SiO}_{2}$
\end{tabular} & 10.51 & 1.958 & 450 & 28.27 & 4.38 \\
\hline $\begin{array}{c}\text { Group B 4\% } \\
\mathrm{SiO}_{2}\end{array}$ & 16.345 & 3.07 & 623.24 & 33.54 & 1.868 \\
\hline $\begin{array}{c}\text { Group C 5\% } \\
\mathrm{SiO}_{2}\end{array}$ & 21.408 & 4.071 & 728.8 & 34.94 & 1.76 \\
\hline $\begin{array}{c}\text { Group D 6\% } \\
\mathrm{SiO}_{2}\end{array}$ & 17.061 & 3.321 & 650.38 & 36.63 & 1.628 \\
\hline
\end{tabular}

ANOVA test showed the difference between groups was highly significant $(\mathrm{p}<0.01)$ for all properties tested. LSD test was conducted to compare means of all experimental groups and control group. There were highly significant differences betweeneach group of the experimental groups and the control group $(\mathrm{p}<0.01)$ for all properties tested. For Munsell visual color test, All specimens of control group (Group A) showed a match with 2.5Y6/4 color tab and all specimens of experimental groups (Group B, C and D) showed a match with $2.5 \mathrm{Y} 6 / 6$ color. There was a slight increase in chroma between experimental group compare to control group. According to the Nickerson's equation, the color difference between these two color notations was equal to 6 . The least possible color difference within the Munsell color system is equal to 2 and the highest difference is equal to 104. All experimental groups showed well dispersion of the nano filler within the silicone matrix under SEM. Filler agglomeration increased as the concentration of filler increased (Fig. 3 to Fig. 5).

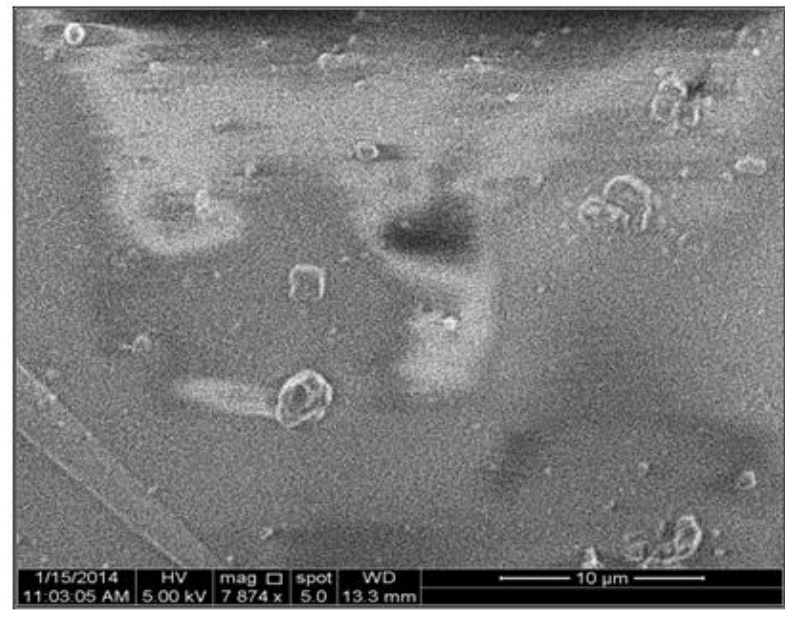

Figure 3: SEM of group B

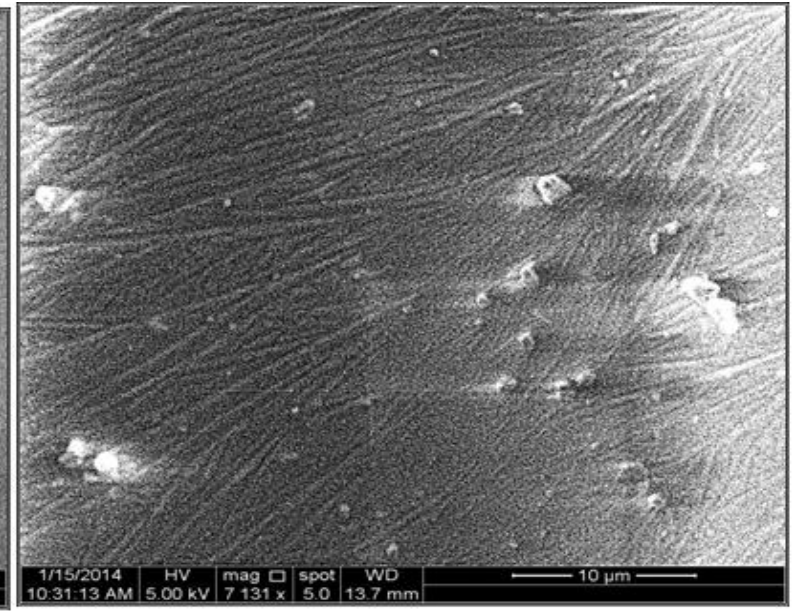

Figure 4: SEM of group C

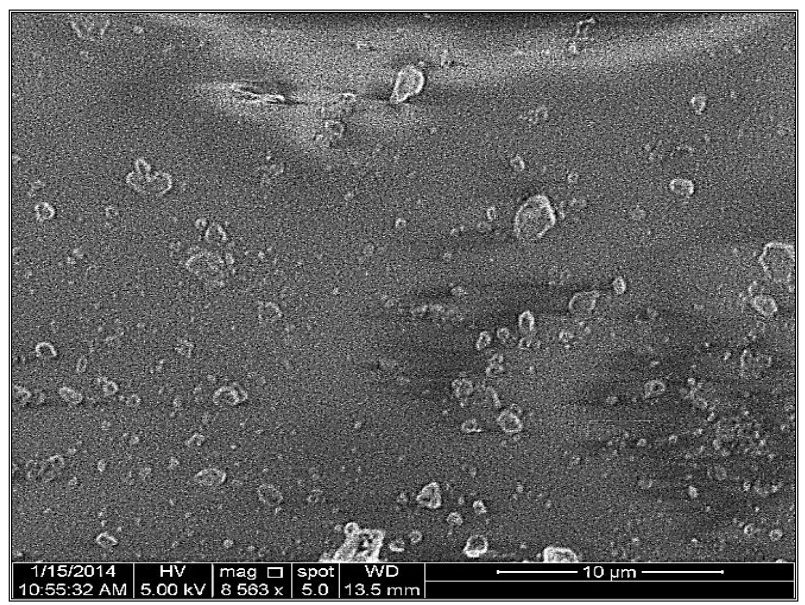

Figure 5: SEM of group D

FTIR indicated that nano silica interacted with the silicone by formation H-bond through the hydroxyl group found on the surface of the silica and the terminalH found on the silicone chains. The change is seen in the spectra range of 3200 to $3600 \mathrm{~cm}^{-1}$ (Fig. 6 to Fig. 8). 


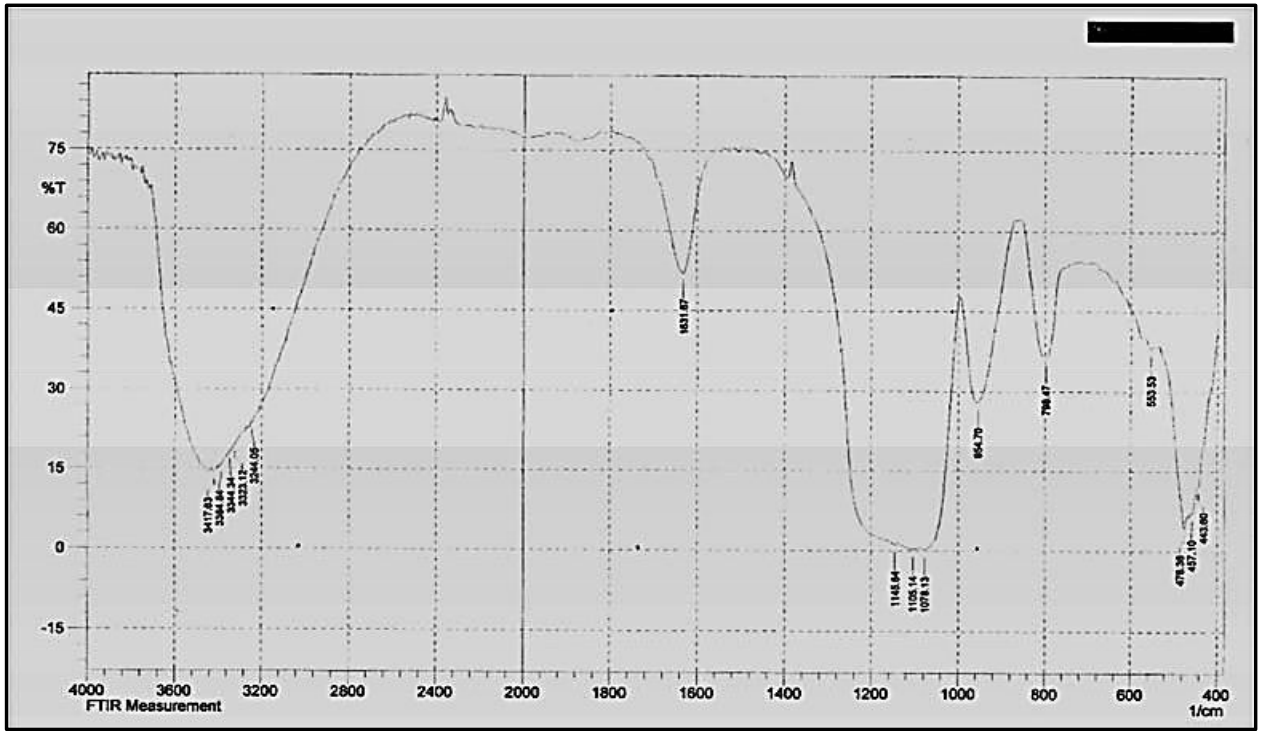

Figure 6:FTIRspectrumofnanoSiO

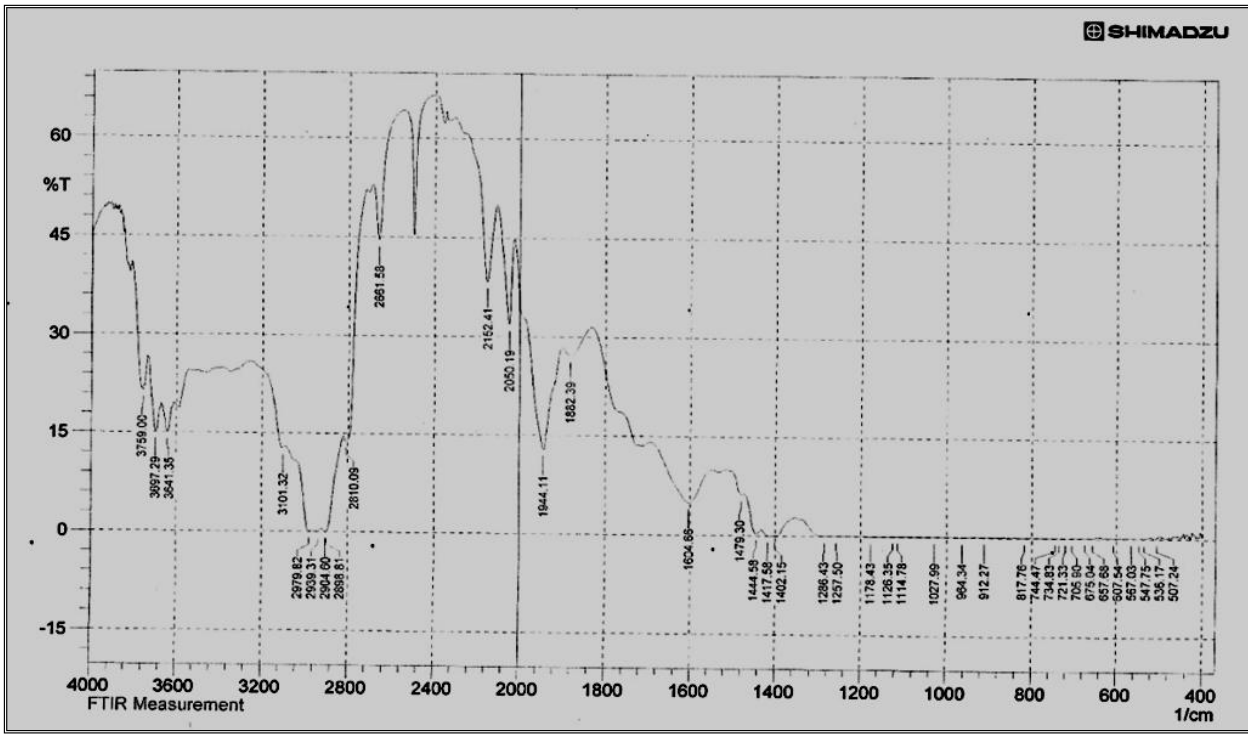

Figure 7: FTIR spectrumofsilicone without nano $\mathrm{SiO}_{2}$

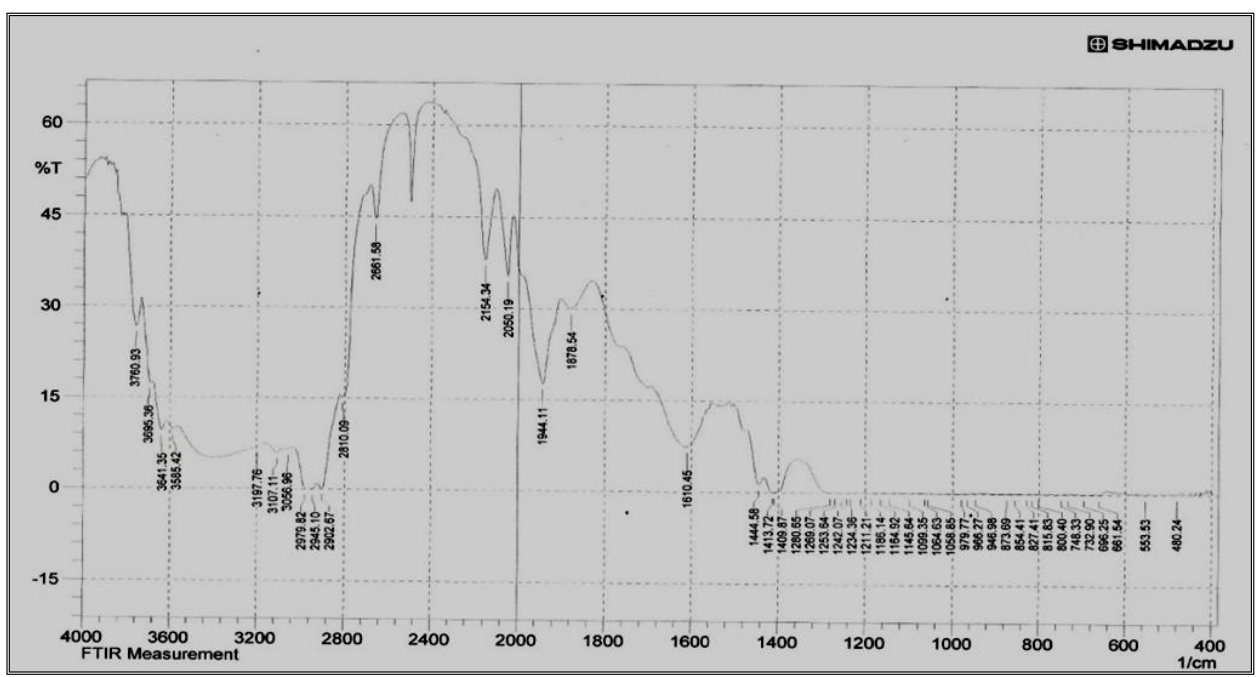

Figure 8: FTIRspectrumofsilicone with nano $\mathrm{SiO}_{2}$ 


\section{Discussion}

Essential properties of maxillofacial silicone elastomers include high tear resistance, high tensile strength and elongation at break, adequate hardness and good color stability. The results of different studies suggest that none of the tested commercial materials fulfilled the above criteria $[5,18,19]$. The addition of fillers is necessary for achieving certain degree of reinforcement that leads to significant improvement of the mechanical properties. The reinforcement depends to a large extent on the polymer properties, filler characteristics (particle size or specific surface area, structure and surface activity), and filler loading (amount of filler) and processing conditions [20-22]. The results from this study indicate that incorporation of nano $\mathrm{SiO}_{2}$ at concentrations of $5 \%$ by weight into a maxillofacial silicone improves tear strength, tensile strength, elongation and hardness. The increase in tear strength can be explained by ability of the polymer to dissipate strain energy near the tip of the growing cracks. As tearing propagates, nano fillers will dissipate the energy within the polymer matrix making it more resistant to tearing and a higher applied loud will be needed to completely break the polymer matrix[23,24]. Tensile strength and elongation of cured silicone elastomer depend greatly on the cross-linking system[5].One of the reinforcement mechanisms of silica is that silica particles act as multifunctional cross-links by formation of strong hydrogen bond between its surface hydroxyl group and PDMS chains; these multifunctional cross-links increase the overall cross-linking density of the polymer and make it more stiff and strong. Under tensional forces, these cross-links prevent the PDMS chains from breaking thus increasing its tensile strength[25]. This fact can explain the increase in tensile strength and elongation at break. The decrease in tear strength, tensile strength and elongation at concentration of $6 \% \mathrm{SiO}_{2}$ could be due to formation of silica agglomerates. Silica agglomerates are formed when two or more silica aggregates bind together by weak electrostatic forces called Van der Waals forces. These agglomerates act as stress concentration areas within the polymer matrix. When the polymer is subjected to external forces, the agglomerates break and weaken the matrix leading to propagation of tear [26, 27]

Shore A hardness results of this study indicated a directly proportional increase in hardness with an increase in filler concentration. This can be explained by the fact that increasing nano filler concentration increases the adsorption of the polymer chain to the filler surface and increases the intermolecular forces. This leads to a rigid polymer with high elastic modulus and more resistance to permanent deformation by penetration [28]. The results of color change tests indicated that the addition of nano silica significantly decreased the light transmission property of maxillofacial silicone and hence decreasing its translucency. This was because fillers tend to fill any spaces or voids within the polymer. Increasing filler load leads to a denser filler-filler network within the polymer matrix. This affects how light interacts with the polymer as some of the light may be partly reflected and partly refracted and some may be absorbed, thus reducing the amount of light transmitted [29].

Reduction of light transmission may be attributed to the scattering effect of silica filler. Light scattering occurs because the index of refraction of silica is different from that of silicone elastomer. The scattering effect causes the material to look darker [30, 31].

These explanations correspond to the findings obtained from the visual color measurement test. Results of the Munsell visual color test indicate that all experimental groups appear slightly darker than control group with an increase in chroma value.

\section{Conclusion}

Reinforcement of Cosmesil M-511 HTV maxillofacial silicone elastomer with 5\% nano $\mathrm{SiO}_{2}$ significantly improves all mechanical properties with a slight change of color seen visually. Also high shear vacuum mixer proved to be a good method of dispersion of the nano fillers into the silicone matrix to a certain concentration as confirmed by SEM.

References

[1] U. Maller, K. Karthik and S. Maller. Maxillofacial Prosthetic Materials - Past and Present Trends,J Ind Aca Dent Spec 1(2), 2010, 42-44.

[2] C. Andres, S. Haug, C. Munoz and G. Bernal. Effects of environmental factors on maxillofacial elastomers: Part I--Literature review, J Prosthet Dent 68(2), 1992, 327-330.

[3] G. Barnhart. A new material and technic in the art of somato-prosthesis,J Dent Res 39, 1960, 836-844.

[4] C. Andres, S. Haug, D. Brown and G. Bernal. Effects of environmental factors on maxillofacial elastomers: Part II--Report of survey,J Prosthet Dent 68(3), 1992, 519-522.

[5] T. Aziz, M. Waters and R. Jagger. Analysis of the properties of silicone rubber maxillofacial prosthetic materials, J Dent 31(1), 2003, 67-74.

[6] T. Aziz, M. Waters and R. Jagger. Development of a new poly(dimethylsiloxane) maxillofacial prosthetic material,J Biomed Mater Res B Appl Biomater 65(2), 2003, 252-261.

[7] K. Bellamy,G. Limbert,M. Waters and J. Middleton. An elastomeric material for facial prostheses: synthesis, experimental and numerical testing aspects,Biomater 24(27), 2003, 5061-5066.

[8] S. Hayashi, K. Fujikiand N. Tsubokawa. Grafting of hyperbranched polymers onto ultrafine silica: postgraft polymerization of vinyl monomers initiated by pendant initiating groups of polymer chains grafted onto the surface, React Funct Polym 46(2), 2000, 193201. 
[9] A. Khanand M. Alam. Synthesis, characterization and analytical applications of a new and novel 'organic-inorganic' composite material as a cation exchanger and Cd(II) ion-selective membrane electrode: polyaniline Sn(IV) tungstoarsenate, React Funct Polym 55(3), 2003, 277-290.

[10] G. Liu, Y. Li, F. Yan, Z. Zhao, L. Zhou and Q. Xue. Effect of Nanoscale $\mathrm{SiO}_{2}$ and $\mathrm{TiO}_{2}$ as the Fillers on the Mechanical Properties and Aging Behavior of Linear Low-Density Polyethylene/Low-Density Polyethylene Blends,J Polym Environ 13(4), 2005, 339348.

[11] N. Al-qenae. Nano ceramic fiber reinforced silicone maxillofacial prosthesis, M.Sc. Thesis, Indiana University School of Dentistry, 2010.

[12] ISO 34-1. Rubber, vulcanized or thermoplastic - Determination of tear strength -- Part 1: Trouser, angle and crescent test pieces, 2010 .

[13] ISO 37. Rubber, vulcanized or thermoplastic - Determination of tensile stress-strain properties, 2011.

[14] ISO 7619-1. Rubber, vulcanized or thermoplastic -- Determination of indentation hardness -- Part 1: Durometer method (Shore hardness), 2010.

[15] Y. Han,Y. Zhao, C. Xie, J. Powersand S. Kiat-amnuay. Color stability of pigmented maxillofacial silicone elastomer: effects of nano-oxides as opacifiers,J Dent 38s, 2010, e100-e105.

[16] ASTM D1535. Standard Practice for Specifying Color by the Munsell System, 2013.

[17] J. Powers and R. Sakaguchi,Craig's restorative dental materials(12 ${ }^{\text {th }}$ ed., Mosby, 2006).

[18] D. Lewis and D. Castleberry. An assessment of recent advances in external maxillofacial materials,J Prosthet Dent 43(4), 1980, 426-432.

[19] G. Polyzoisand M. Frangou. Bonding of silicone prosthetic elastomers to three different denture resins, Int J Prosthodont 15(6), 2002, 535-538.

[20] F. Yatsuyanagi,N. Suzuki, M. Ito and H. Kaidou. Effects of secondary structure of fillers on the mechanical properties of silica filled rubber systems,Polymer 42(23), 2001, 9523-9529.

[21] C. Robertson, C. Lin, M. Rackaitisand C. Roland. Influence of Particle Size and Polymer-Filler Coupling on Viscoelastic Glass Transition of Particle-Reinforced Polymers, Macromol 41(7), 2008, 2727-2731.

[22] T. Mahrholz, J. Stängle and M. Sinapius. Quantitation of the reinforcement effect of silica nanoparticles in epoxy resins used in liquid composite moulding processes,J Comp Part A: App Sci Manu 40(3), 2009, 235-243.

[23] J. Donnet and E. Custodero,Reinforcement of Elastomers by Particulate Fillers in Science and Technology of Rubber( $3^{\text {rd }}$ ed., Academic Press, 2005, 367-400).

[24] L. Sun, R. Gibson, F. Gordaninejad and J. Suhr. Energy absorption capability of nanocomposites: A review,Comp Sci Tech 69(14), 2009, 2392-2409.

[25] A. Andreopoulos and M. Evangelatou. Evaluation of various reinforcements for maxillofacial silicone elastomers,J Biomater Appl 8(4), 1994, 344-360.

[26] J. Brinke, S. Debnath, L. Reuvekamp and J. Noordermeer. Mechanistic aspects of the role of coupling agents in silica-rubber composites,Comp Sci Tech 63(8), 2003, 1165-1174.

[27] Y. Han, S. Kiat-amnuay, J. Powers and Y. Zhao. Effect of nano-oxide concentration on the mechanical properties of a maxillofacial silicone elastomer, J Prosthet Dent 100(6), 2008, 465-473.

[28] A. Hasse, A. Wehmeier and H. Luginsland. Crosslinking and reinforcement of silica/silane-filled rubber compounds, Rub World 230(1), 2004, 22.

[29] S. Mousavinasab,Effects of Filler Content on Mechanical and Optical Properties of Dental Composite Resin in Metal, Ceramic and Polymeric Composites for Various Uses( $1^{\text {st }}$ ed., InTech, 2001).

[30] S. Mitra, D. Wu and B. Holmes. An application of nanotechnology in advanced dental materials,J Am Dent Assoc 134(10), 2003, 1382-1390.

[31] S. Garoushi, P. Vallittuand L. Lassila. Effect of Short Fiber Fillers on the Optical Properties of Composite Resins,J Mater Sci Res 1(2), 2012, 174-180. 